\title{
AN EXPERIMENTAL INVESTIGATION OF THE DIELECTRIC PROPERTIES OF THERMALLY EVAPORATED RARE EARTH OXIDES FOR USE IN THIN FILM CAPACITORS
}

\author{
A. T. FROMHOLD, JR. and W. D. FOSTER $\dagger$ \\ Department of Physics, Auburn University, Auburn, Alabama 36830, U.S.A.
}

(Received July 25, 1975; in final form January 30, 1976)

\begin{abstract}
An experimental survey of rare earth oxides for use in thin film capacitors has been completed. Dielectric properties measured at $300^{\circ} \mathrm{K}$ are reported for thermally evaporated oxides 300 to $6000 \AA$ in thickness of the metals, $\mathrm{La}, \mathrm{Ce}$, $\mathrm{Pr}, \mathrm{Nd}, \mathrm{Sm}, \mathrm{Gd}, \mathrm{Dy}, \mathrm{Ho}, \mathrm{Er}, \mathrm{Yb}$; Y, Sc, and also, V. Thin evaporated aluminum electrodes were utilized to impress voltages in the range zero to $75 \mathrm{~V}$ across the oxide layers. Dielectric breakdown strengths in excess of $5 \times 10^{6} \mathrm{~V} / \mathrm{cm}$ were observed. Relative dielectric constants measured for the oxides range from two to twenty, and measured capacitances were as high as $156 \times 10^{-9} \mathrm{~F} / \mathrm{cm}^{2}$. The oxides of $\mathrm{Ce}, \mathrm{La}, \mathrm{Nd}, \mathrm{Gd}, \mathrm{Pr}$, and Er show the most promise as potential materials for use in thin film capacitors.
\end{abstract}

\section{INTRODUCTION}

Harrop ${ }^{1}$ provides an excellent elementary introduction to the field of dielectrics, while the monumental compilation of reviews of the various aspects of preparation, nature, properties, and applications of thin film technology edited by Maissel and Glang ${ }^{2}$ constitutes an authoritative reference work on the many technical aspects of thin film capacitor materials. Thus it would be superfluous to go into these matters in any detail in this short paper. Gerstenberg ${ }^{3}$, as an example, has given a beautiful discussion of the properties and experimental factors which influence the quality of thin film capacitors. Among the many properties which can be considered are capacitance per unit area, dissipation factor for dielectric loss $(\tan \delta)$, temperature coefficient of capacitance, time constant, working vol tage, frequency response, breakdown field, charge storage capability, energy storage capability, stresses, strains, mechanical stability, chemical stability, amorphous or crystalline nature of the dielectric, the dielectric constant, local areas of nonstoichiometry, impurities, and macroscopic defects such as cracks. Among the many experimental factors which have received attention ${ }^{2}$ are the variables of electrode material, electrode thickness, method of formation of the dielectric,

$\dagger$ Present Address: 189 Grandview Avenue, Valparaiso, Florida 32580 . aging coupled with various temperature and pressure treatments, and ambient conditions such as the presence of water vapor.

There are many methods for formation of thin dielectric films, such as thermal evaporation, thermal oxidation, anodic oxidation, d.c. and r.f. enhanced oxidation, reactive sputtering in the presence of d.c., a.c., or glow discharges, flash evaporation, electron beam evaporation, and vapor phase deposition. Each method is typified by a characteristic set of variables. For example, with thermal evaporation one must consider the variables of ambient pressure, substrate temperature, source-to-substrate distance, and evaporation (or deposition) rate, to name only a few.

Harrop and Campbell 4,5 have drawn up "target specifications" regarding materials for use in thin film capacitors and have provided useful lists of the best materials. These authors have suggested the consideration of two separate categories of capacitors, referred to as "high capacitance", and "low loss", respectively, and have offered the following general criteria for the two categories:

A. High Capacitance Capacitors:

1) High Capacity per unit area, nominally $C>0.1 \mu \mathrm{F} / \mathrm{cm}^{2}$

2) Low Dielectric Loss, nominally $\tan \delta<1 \%$

3) Working Voltage $>10 \mathrm{~V}$

4) Time Constant $\tau>50$ to $100 \mathrm{~s}$ 
5) Moderate Temperature Coefficient of Capacitance, nominally $\left|\gamma_{\mathrm{c}}\right|<500 \mathrm{ppm} /{ }^{\circ} \mathrm{C}$

\section{B. Low Loss Capacitors:}

1) As high a Capacity per unit area as possible, nominally $C>0.01 \mu \mathrm{F} / \mathrm{cm}^{2}$

2) Low Dielectric Loss, nominally $\tan \delta<0.01$ to $0.1 \%$

3) Working Voltage $\geqslant 10 \mathrm{~V}$

4) Time Constant $\tau>1000 \mathrm{~s}$

5) Small Temperature Coefficient of Capacitance, nominally $\left|\gamma_{\mathrm{c}}\right| \leqslant 10$ to $20 \mathrm{ppm} /{ }^{\circ} \mathrm{C}$.

By taking the criterion that the working voltage should be approximately one-half of the breakdown voltage $^{5}$, it can be seen that a high breakdown field is required. Specifically, the breakdown field must be greater than $2 \times 10^{6} \mathrm{~V} / \mathrm{cm}$ for a $1000 \AA$ thick dielectric film. Since high capacity is important for both categories listed above, dielectrics with the highest permittivity consistent with high breakdown strength is required. It has been suggested ${ }^{5}$ from a comparison of maximum breakdown field with the reciprocal of the $\AA /$ volt ratio for anodically-formed oxides that breakdown itself may be governed by the same process as field-assisted ionic transport. The correlation between the values for these two phenomena is indeed striking ${ }^{5}$. Dielectrics having high permittivity require correspondingly larger quantities of charge to produce a given voltage, in accordance with Poisson's equation of electrostatics. To the extent that breakdown is a random process which initiates statistically at individual charges or charged ions which create the electric field (these charges probably being predominantly at the interfaces), high permittivity dielectrics could be expected to have lower breakdown strengths.

Despite the great variety of materials thus far studied ${ }^{4,5}$, there is always an interest in, and curiosity concerning, the properties of those materials which have not yet been examined. The purpose of the present experimental survey was to investigate experimentally the properties of the rare earth oxides for use in thin film capacitors. Our hope was to help furnish a wider variety of dielectric materials for thin film application. The rare earth and transition metal oxides have many of the necessary characteristics of promising dielectric materials. Earlier work on these materials has focused attention on their vaporization and optical properties $6,7,8$, although some experimental work has been aimed at determining the dielectric properties of the oxides of $\mathrm{Y}, \mathrm{Yb}$, and
Dy $9,10,11$. The present study has proved the feasibility of evaporating thin dielectric films of these materials in a high vacuum system. A list of the oxides investigated in this study together with the nominal purity and source of procurement are listed in Table I.

TABLE I

Oxides investigated, nominal purity, and source

\begin{tabular}{lll}
\hline Oxide & Purity $(\%)$ & Source \\
\hline Scandium & 99.9 & $\mathrm{a}$ \\
Vanadium & 99.9 & $\mathrm{~b}$ \\
Yttrium & 99.9 & $\mathrm{a}$ \\
Lanthanum & 99.0 & $\mathrm{c}$ \\
Cerium & 99.9 & $\mathrm{a}$ \\
Praseodymium & 99.9 & $\mathrm{a}$ \\
Neodymium & 99.9 & $\mathrm{a}$ \\
Samarium & 99.9 & $\mathrm{c}$ \\
Gadolinium & 99.9 & $\mathrm{a}$ \\
Dysprosium & 99.9 & $\mathrm{a}$ \\
Holmium & 99.9 & $\mathrm{a}$ \\
Erbium & 99.9 & $\mathrm{a}$ \\
Ytterbium & 99.9 & $\mathrm{a}$ \\
\hline
\end{tabular}

a. Bernard Ring Inc., 239 Park Avenue South, New York, New York 10003

b. Gallard Schlesinger Mfg. Corp. Carle Place, New York

c. Electronic Space Products, Inc. 854 So. Robertson Blvd., Los Angeles, California 90035

\section{EXPERIMENTAL PROCEDURE}

\subsection{Substrate Preparation}

The substrate chosen for fabricating the capacitors was a 3 in $\times 1$ in soft-glass microscope slide. Liquid silver tabs were "fired on" to the substrate prior to evaporation by heating the slide to $600^{\circ} \mathrm{C}$. Electrical contact was made to the "fired on" silver tabs by soldering copper wires with a pencil-type solder gun. This procedure was carried out prior to evaporation to avoid the possibility of heat damage to the capacitors. These contacts proved to have excellent mechanical and electrical qualities. The substrates were then vibrated in several rinses of deionized water with a Bendix ultrasonic cleaner. They were then dried in a hot air blast (approximately $100^{\circ} \mathrm{C}$ ) for 5 to 10 minutes.

\subsection{Evaporation Procedure}

The vacuum system for evaporation consisted of a NRC 4 in silicon oil diffusion pump backed by a 
15 CFM Welch mechanical pump. The 14 in $\times 24$ in pyrex bell jar was sealed to a 20 in diameter stainless steel base plate by means of a viton " $L$ " shaped gasket. Ten 1 in holes were drilled on a 4 in radius to accommodate high current feed-throughs for evaporation. The oxides were evaporated from tungsten boats and the electrode material was evaporated from tungsten filaments by means of the resistance heating technique. Power to the filament and boat was supplied by two step-down transformers and a Superior Electric Powerstat with a $220 \mathrm{~V}$ input.

Ultimate pressure varied from $4 \times 10^{-7}$ to $3 \times 10^{-6}$ torr, depending on pump-down time following system exposure to air. Evaporation pressures ranged from $6 \times 10^{-7}$ to $5 \times 10^{-6}$ torr for the electrode material and $2 \times 10^{-5}$ to $8 \times 10^{-5}$ torr for the oxides. The majority of the oxides were evaporated in the upper portions of this pressure range.

The filaments, boats, oxides and electrode material were carefully out-gassed prior to evaporation. To avoid contamination of the substrate and evaporated films, the substrate was shielded during outgassing. The evaporant source to substrate distance was approximately $5 \mathrm{in}$. The procedure was to first evaporate a strip of aluminum $\frac{1}{8}$ in by $2 \frac{5}{8}$ in

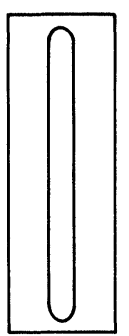

(1)

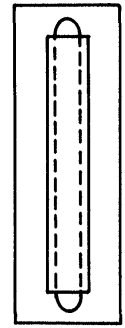

(2)

(a)

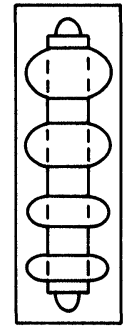

(3)

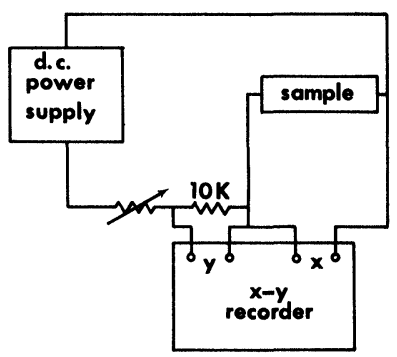

(b)

FIGURE 1 (a) Evaporation sequence and sample geometry. (b) Circuit employed to obtain current-voltage data. for the base electrode. An oxide strip $\frac{1}{4}$ in by $2 \frac{3}{8}$ in was then evaporated over the base electrode. The extra width was necessary to insure complete coverage of the base electrode, thereby eliminating the possibility of edge effects. The counterelectrodes were then evaporated over the oxide; these consisted of four aluminum strips oriented perpendicular to the base electrode. The width of these strips were $\frac{1}{4}, \frac{7}{32}$, $\frac{3}{16}$, and $\frac{1}{8}$ in, and are designated by A, B, C, and D, respectively. (The geometrical areas of the capacitors were thus $0.20,0.18,0.15$, and $0.10 \mathrm{~cm}^{2}$, respectively.) The distance between counterelectrodes was $\frac{11}{32}$ in. The fabrication sequence and sample geometry are shown in Figure 1a. Three samples could be prepared in each run by utilizing a rotating stainless steel substrate holder and mask arrangement.

The temperature of the evaporant source was measured with a Leeds and Northrup optical pyrometer and found to vary from 2000 to $2300^{\circ} \mathrm{C}$ during evaporation of the oxides. Temperature of the substrate was monitored with an alumel-chromel type thermocouple and observed to be $25^{\circ} \mathrm{C}$ during deposition of electrode material and approximately $50^{\circ} \mathrm{C}$ during deposition of the oxides. This elevated substrate temperature was due to the large amount of heat necessary to accomplish evaporation of the oxides. An approximate measure of the deposition rate of the oxide films was determined by calculating the ratio of film thickness to evaporation time.

\subsection{Measurement}

A schematic diagram of the circuit used to obtain current-voltage data ${ }^{12-15}$ is shown in Figure $1 b$. Measurements were made both in vacuum and at atmospheric pressure and room temperature. $\mathbf{A}$ terminal strip was mounted to the substrate holder allowing electrical connections to be made to the substrate inside the vacuum system. Electrical connection to the outside test circuit was made through a NRC eight-pin instrument feed-through.

Capacitance was measured with a General Radio Company $1000 \mathrm{~Hz}$ general purpose bridge. The maximum error as stated by the manufacturer is $\pm 2 \%$. Oxide film thickness was measured to an accuracy of $\pm 200 \AA$ with a series MMA-MMU Metallurgical Microscope by means of the Tolansky method $^{16}$. The capacitance formed by an insulator separated by two parallel plate conductors is expressed by

$$
C=8.842 \times 10^{-8} \frac{\epsilon_{\mathrm{r}} A}{L}
$$


where $C$ is the capacitance in microfarads, $\epsilon_{\mathrm{r}}$ is the relative dielectric constant $\left(\epsilon / \epsilon_{0}\right)$ of the material, $A$ is the area of the capacitor in $\mathrm{cm}^{2}$, and $L$ is the thickness of the dielectric in $\mathrm{cm}$. Values of the dielectric constants were calculated from this formula.

\section{RESULTS}

\subsection{General}

Electron diffraction patterns showed that the starting materials (see Table I) were generally polycrystalline oxides, as for example, $\mathrm{CeO}_{2}, \mathrm{Gd}_{2} \mathrm{O}_{3}$, and $\mathrm{Er}_{2} \mathrm{O}_{3}$. In some cases, however, the hydroxides were found in the as-purchased starting materials, as, for example, $\mathrm{La}(\mathrm{OH})_{3}$ and $\mathrm{Nd}(\mathrm{OH})_{3}$. After evaporation, the thin film dielectric could generally be identified by electron diffraction as made up of the expected finegrained polycrystalline oxide ${ }^{14}$. In a brief survey such as this, it was not possible to do a more comprehensive job of characterizing the materials and separating out the effects of stoichiometry, uniformity, and crystallinity.

The capacitors were examined with a metallurgical microscope, (utilizing a magnification of 400 ) before application of voltage. Immediately after removal from the vacuum system, the electrodes and exposed oxide appeared smooth and continuous. After an hour or so of exposure to normal atmospheric conditions, the exposed oxide developed dark spots and apparent discontinuities. These effects were most pronounced around the edge of the active area of a capacitor. For aluminum electrodes, such defects apparently did not have any effect on the quality of the capacitor, insofar as data taken immediately upon removal from the vacuum system did not differ markedly from that taken following an hour or so exposure to laboratory atmosphere. The characteristics obtained in vacuum, however, varied markedly from any taken at atmospheric pressure, as discussed in greater detail in Section 3.4. Several unsuccessful attempts were made to use copper and silver as the electrode material. For these capacitors, portions of the top electrode would disappear within an hour following removal from the vàcuum system. Sufficient electrode material would ultimately disappear to give rise to an open circuit across the capacitor. It is believed that the electrode material actually diffused into the oxide.

Observations during the application of voltage revealed that dielectric breakdown in thin film capacitors occurs over a highly localized region. Breakdown is accompanied by the emission of white light

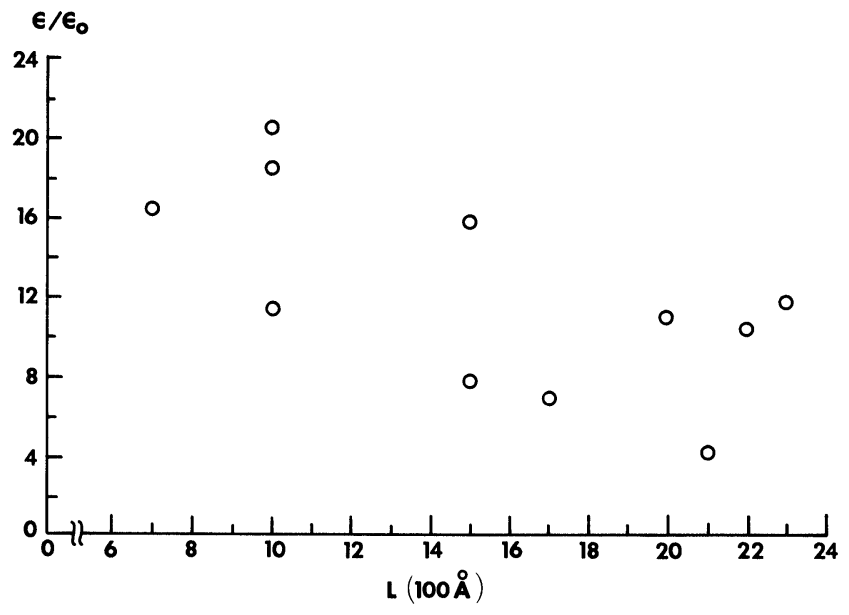

FIGURE 2 Relative dielectric constant versus film thickness for gadolinium oxide.

and destruction of electrode material. This phenomenon was studied extensively utilizing optical microscopy techniques. No regularities with regard to size, shape, or location of such electrode destruction were noted. In general, the films were observed to recover almost immediately from the dielectric breakdown. Some capacitors underwent such breakdown, followed by a very rapid self-healing process, a number of times without further increase in voltage. Others required 10 to $15 \mathrm{~V}$ before suffering additional breakdowns following the onset of the phenomenon. Breakdown strengths are quoted in terms of the average value of the onset of the local dielectric breakdown. Further voltage cycles continued to create local breakdowns until sufficient electrode material was destroyed to give rise to an open circuit behavior.

\subsection{Geometry and Forming Properties}

Figure 2 illustrates the variation of dielectric constant with film thickness for gadolinium oxide. Each point represents the average obtained from the individual capacitors of a given sample. For neodymium oxide the trend seems to be toward increasing dielectric constant with increasing film thickness, while for gadolinium oxide there is definitely a decrease in dielectric constant with increasing film thickness. For all oxides investigated, the dielectric constant as well as the quality of the resulting capacitors was found to vary with evaporation parameters (i.e., ultimate pressure, evaporation pressure, current and time). 


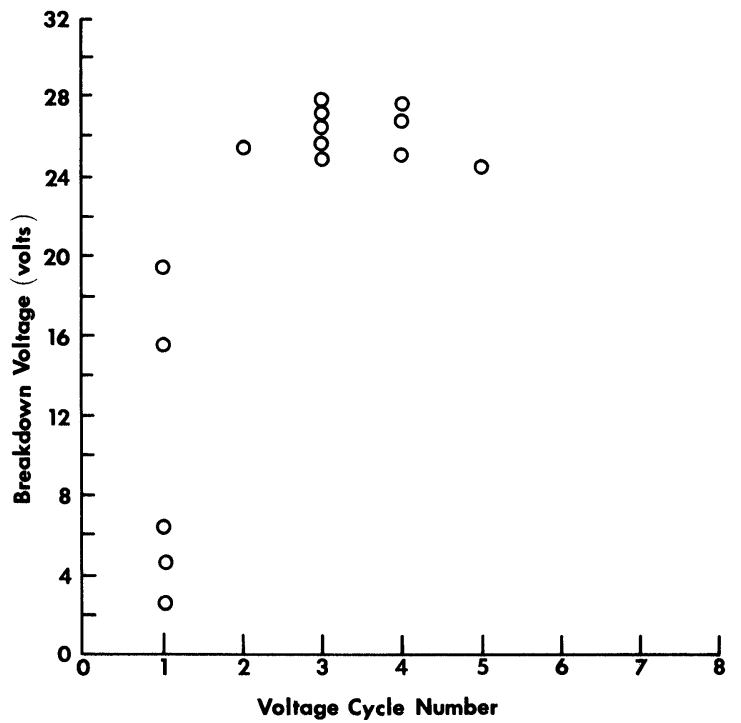

FIGURE 3 Breakdown voltage versus current-voltage cycle for lanthanum oxide capacitor La-3-A.

Figures 3 and 4 illustrate the typical variation in dielectric breakdown voltage with voltage cycle number. A voltage cycle is defined as the process of increasing the voltage across the film from zero to some maximum value and then decreasing back to zero. In general, the maximum value was greater than the voltage corresponding to onset of dielectric breakdown. Several local dielectric breakdowns occur on a single voltage cycle. In general the breakdown voltage depends on the history of the capacitor, and increases with increasing voltage cycle number. Local

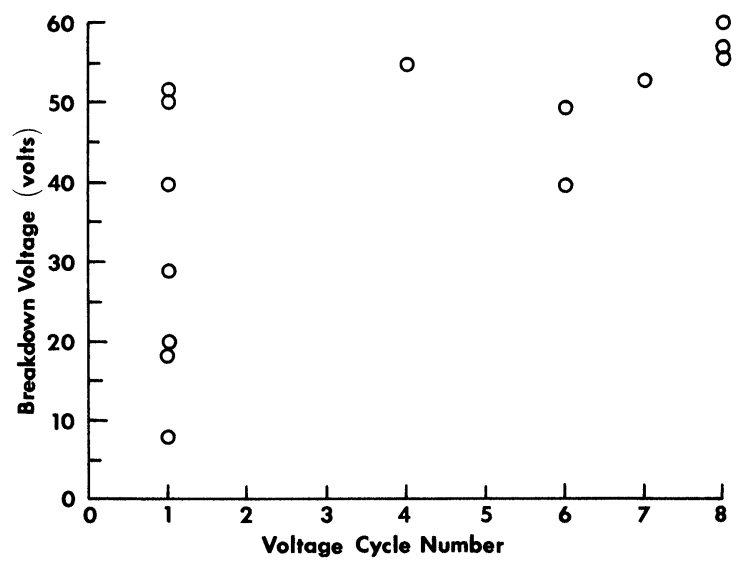

FIGURE 4 Breakdown voltage versus current-voltage cy cle for neody mium oxide capacitor Nd-1-A. dielectric breakdown initially occurs at low field strengths (e.g., $0.43 \times 10^{6} \mathrm{~V} / \mathrm{cm}$ for cerium oxide) and increases to some higher value $\left(0.94 \times 10^{6} \mathrm{~V} / \mathrm{cm}\right)$ after five or six voltage cycles. In some cases the breakdown voltage remained relatively constant, following the initial "forming" dielectric breakdowns (see Figure 3), while in other cases the breakdown voltage was more erratic following the initial breakdowns.

\subsection{Dielectric and Breakdown Properties}

The observed properties of the oxides investigated in air are tabulated in Table II. (Values of current density quoted in this particular table have not been corrected for current drawn by the Moseley X-Y recorder since this is unnecessary for the present purposes. For values of $\mathrm{V}_{\text {Avg }}$ above $15 \mathrm{~V}$ the correction factor is $3 \times 10^{-4} \mathrm{~mA} / \mathrm{V}$; below $15 \mathrm{~V}$, the correction factor is $1 \times 10^{-3} \mathrm{~mA} / \mathrm{V}$.) The capacitors are designated by giving oxide, sample number and counterelectrode. For example, Ce-1-A refers to the capacitor formed between the base electrode and counterelectrode $\mathrm{A}$ from the first sample fabricated using cerium oxide as the dielectric material. As stated above, the geometrical areas corresponding to the counterelectrodes are as follows: electrode A: $0.20 \mathrm{~cm}^{2}$; electrode B: $0.18 \mathrm{~cm}^{2}$; electrode C: $0.15 \mathrm{~cm}^{2}$; electrode D: $0.10 \mathrm{~cm}^{2}$. Brief summaries of the experimental results for each oxide are given in the subsequent paragraphs.

3.3.1 Cerium oxide Two samples of this oxide were prepared and both revealed excellent dielectric properties. Sample number one (6440 \& oxide film thickness) yielded capacitance measurements on all four capacitors ranging from $3.0 \times 10^{-9} \mathrm{~F}$ to $5.7 \times 10^{-9} \mathrm{~F}$. This sample had the highest average dielectric constant (19.0) of all oxides investigated. Leakage current versus voltage was relatively smooth with only a few local dielectric breakdowns occurring. Sample number two $(2769 \AA)$ also had stable behavior with the occurrence of only a small number of local dielectric breakdowns. Capacitance measurements were obtained on two of the capacitors from this sample with values of $1.5 \times 10^{-9} \mathrm{~F}$ and $1.6 \times 10^{-9} \mathrm{~F}$. Both samples were fabricated with relative ease. Cerium oxide is the most abundant of the rare earth oxides ${ }^{17}$ and shows a great deal of promise as a dielectric material for use in thin film capacitors. 
TABLE II

Table of measured properties of the oxides investigated

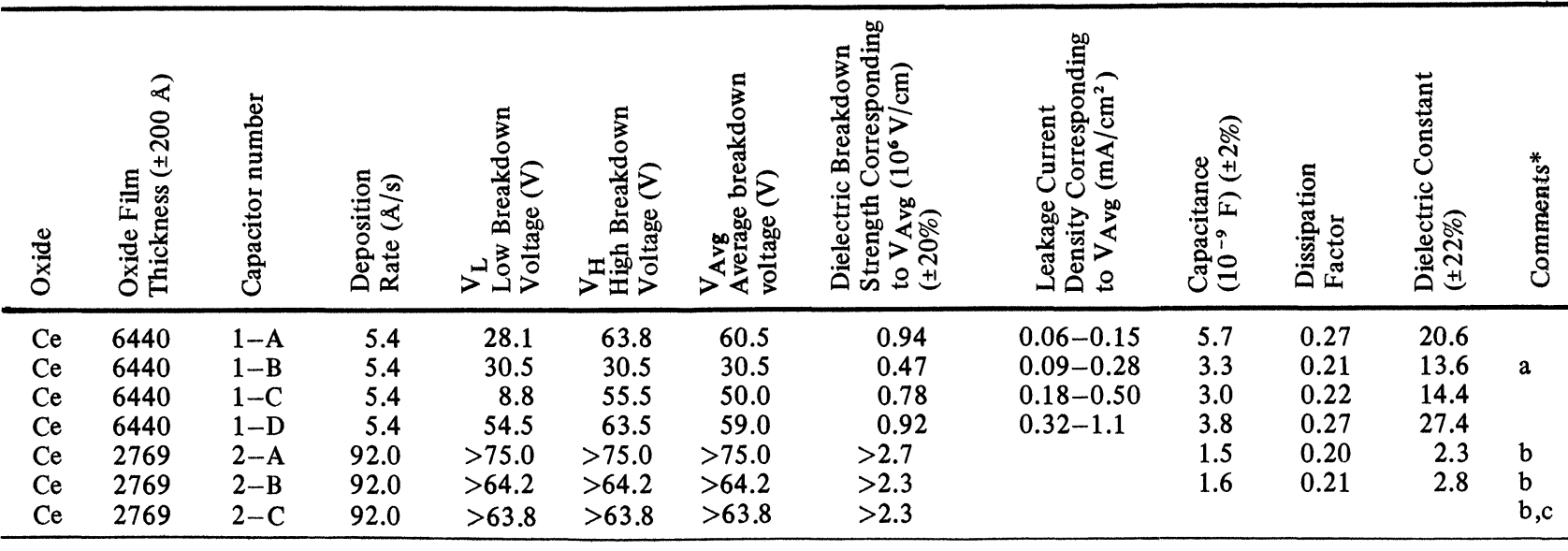

\begin{tabular}{|c|c|c|c|c|c|c|c|c|c|c|c|c|}
\hline $\begin{array}{l}\mathrm{La} \\
\mathrm{La} \\
\mathrm{La} \\
\mathrm{La}\end{array}$ & $\begin{array}{l}322 \\
322 \\
322 \\
322\end{array}$ & $\begin{array}{l}3-\mathrm{A} \\
3-\mathrm{B} \\
3-\mathrm{C} \\
3-\mathrm{D}\end{array}$ & $\begin{array}{l}1.0 \\
1.0 \\
1.0 \\
1.0\end{array}$ & $\begin{array}{r}2.5 \\
8.2 \\
0.4 \\
16.8\end{array}$ & $\begin{array}{l}27.8 \\
33.5 \\
29.2 \\
71.8\end{array}$ & $\begin{array}{l}25.6 \\
27.2 \\
27.1 \\
29.4\end{array}$ & $\begin{array}{l}7.9 \\
8.9 \\
8.9 \\
8.9\end{array}$ & $\begin{array}{l}1.2-1.5 \\
0.23-1.9 \\
0.36-2.2 \\
0.45-0.55\end{array}$ & $\begin{array}{r}11.0 \\
20.5 \\
6.2\end{array}$ & $\begin{array}{l}0.14 \\
0.15 \\
0.28\end{array}$ & $\begin{array}{l}2.3 \\
4.9 \\
2.2\end{array}$ & $c$ \\
\hline & & & & & & & 8.7 & & & & $3.1 \dagger$ & \\
\hline $\begin{array}{l}\mathrm{Pr} \\
\mathrm{Pr} \\
\mathrm{Pr} \\
\mathrm{Pr} \\
\mathrm{Pr} \\
\mathrm{Pr} \\
\mathrm{Pr} \\
\mathrm{Pr}\end{array}$ & $\begin{array}{l}1265 \\
1265 \\
1265 \\
1265 \\
1288 \\
1288 \\
1288 \\
1288\end{array}$ & $\begin{array}{l}1-\mathrm{A} \\
1-\mathrm{B} \\
1-\mathrm{C} \\
1-\mathrm{D} \\
2-\mathrm{A} \\
2-\mathrm{B} \\
2-\mathrm{C} \\
2-\mathrm{D}\end{array}$ & \begin{tabular}{r|}
1.1 \\
1.1 \\
1.1 \\
1.1 \\
10.7 \\
10.7 \\
10.7 \\
10.7
\end{tabular} & $\begin{array}{r}2.5 \\
8.4 \\
11.2 \\
5.8 \\
26.4 \\
22.2\end{array}$ & $\begin{array}{l}60.8 \\
58.8 \\
62.6 \\
59.8 \\
40.3 \\
22.2\end{array}$ & $\begin{array}{l}53.6 \\
41.0 \\
51.0 \\
42.1 \\
34.3 \\
22.2\end{array}$ & $\begin{array}{l}4.2 \\
3.2 \\
4.0 \\
3.3 \\
2.7 \\
1.7\end{array}$ & $\begin{array}{l}0.22-0.65 \\
0.12-0.45 \\
0.18-0.40 \\
0.20-0.65 \\
0.29-0.40 \\
0.10-0.17\end{array}$ & $\begin{array}{r}2.4 \\
5.4 \\
1.1 \\
1.3 \\
16.0 \\
15.0 \\
12.2 \\
8.7\end{array}$ & $\begin{array}{l}0.22 \\
0.21 \\
0.19 \\
0.20 \\
0.04 \\
0.04 \\
0.05 \\
0.08\end{array}$ & \begin{tabular}{r|}
1.7 \\
4.4 \\
1.0 \\
1.8 \\
11.6 \\
12.4 \\
11.7 \\
12.6
\end{tabular} & $\begin{array}{l}\mathrm{a} \\
\mathrm{e} \\
\mathrm{a}\end{array}$ \\
\hline
\end{tabular}

\begin{tabular}{|c|c|c|c|c|c|c|c|c|c|c|c|c|}
\hline $\mathrm{Nd}$ & 955 & $1-\mathrm{A}$ & 15.9 & 7.8 & 60.0 & 54.6 & 5.7 & $0.13-0.25$ & 14.9 & 0.04 & 8.0 & \\
\hline $\mathrm{Nd}$ & 955 & $1-B$ & 15.9 & 12.2 & 59.6 & 48.2 & 5.0 & $0.11-2.1$ & 14.1 & 0.05 & 8.6 & \\
\hline $\mathrm{Nd}$ & 955 & $1-\mathrm{C}$ & 15.9 & 22.6 & 61.5 & 50.3 & 5.3 & $0.14-2.0$ & 11.9 & 0.04 & 8.5 & \\
\hline $\mathrm{Nd}$ & 955 & $1-D$ & 15.9 & & & & & & & & & \multirow[t]{5}{*}{ e } \\
\hline $\mathrm{Nd}$ & 644 & $2-A$ & 10.7 & 0.4 & 4.3 & 3.1 & 0.5 & $0.40-1.1$ & 31.2 & 0.18 & 11.2 & \\
\hline $\mathrm{Nd}$ & 644 & $2-B$ & 10.7 & 3.4 & 27.8 & 13.1 & 2.0 & $0.13-0.18$ & 25.0 & 0.13 & 10.3 & \\
\hline $\mathrm{Nd}$ & 644 & $2-C$ & 10.7 & 7.7 & 42.0 & 20.1 & 3.1 & $0.24-0.43$ & 20.4 & 0.12 & 9.8 & \\
\hline \multirow[t]{2}{*}{$\mathrm{Nd}$} & 644 & $2-\mathrm{D}$ & 10.7 & 5.5 & 48.0 & 14.8 & 2.3 & $0.20-1.9$ & 13.9 & 0.15 & 10.1 & \\
\hline & & & & & & & & & & & 9.5 & \\
\hline Gd & 2254 & $1-\mathrm{A}$ & 37.5 & 46.6 & 70.1 & 62.6 & 2.8 & $0.19-0.20$ & 8.7 & 0.01 & 10.7 & \\
\hline Gd & 2254 & $1-B$ & 37.5 & 42.3 & 74.0 & 64.9 & 2.9 & $0.17-0.22$ & 8.9 & 0.01 & 12.8 & \\
\hline $\mathrm{Gd}$ & 2254 & $1-\mathrm{C}$ & 37.5 & $>75.0$ & $>75.0$ & $>75.0$ & $>3.3$ & & 7.0 & 0.01 & 11.7 & b \\
\hline Gd & 2254 & $1-D$ & 37.5 & & & & & & & & & f \\
\hline
\end{tabular}




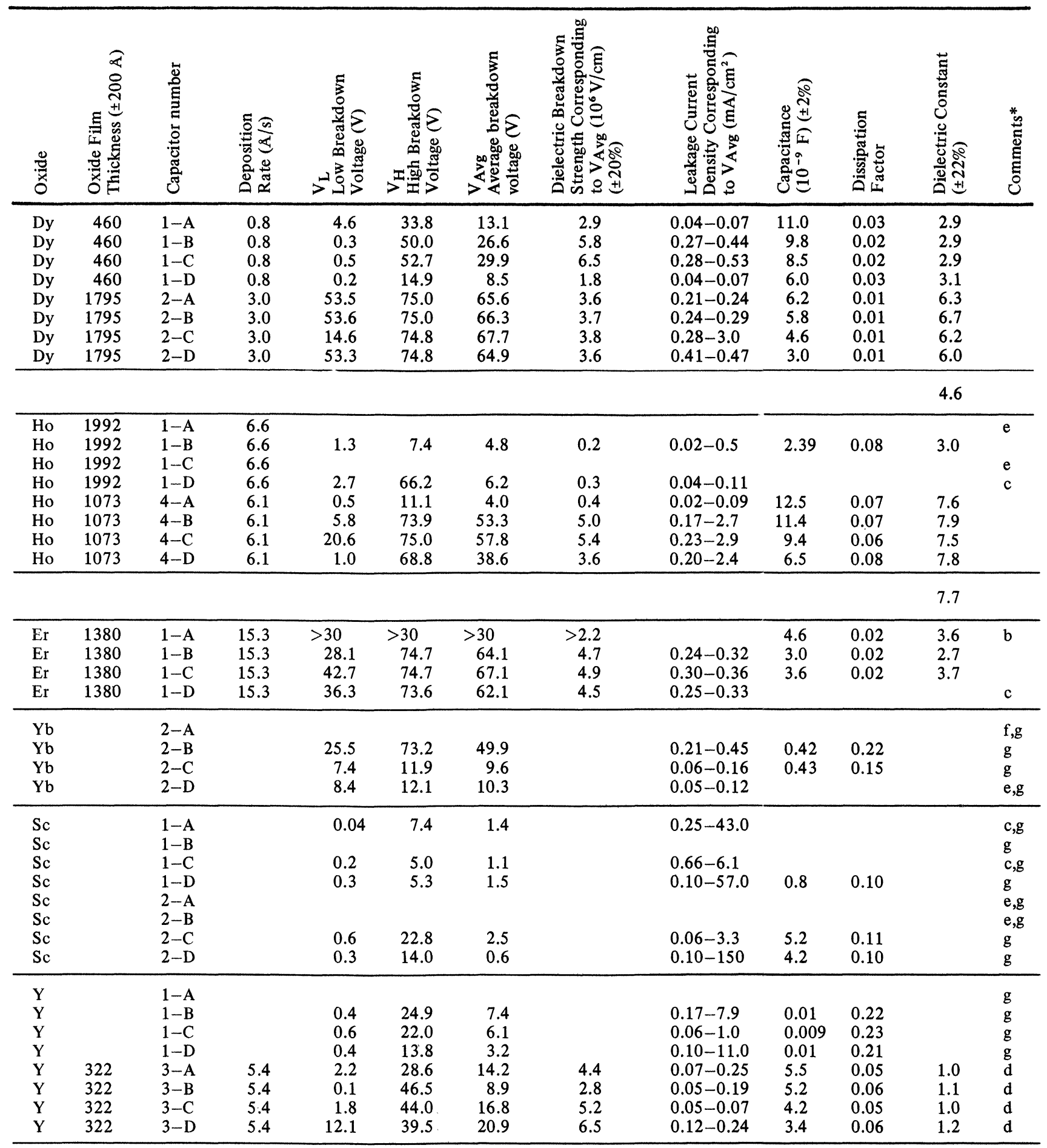


TABLE II (continued)

Table of measured properties of the oxides investigated

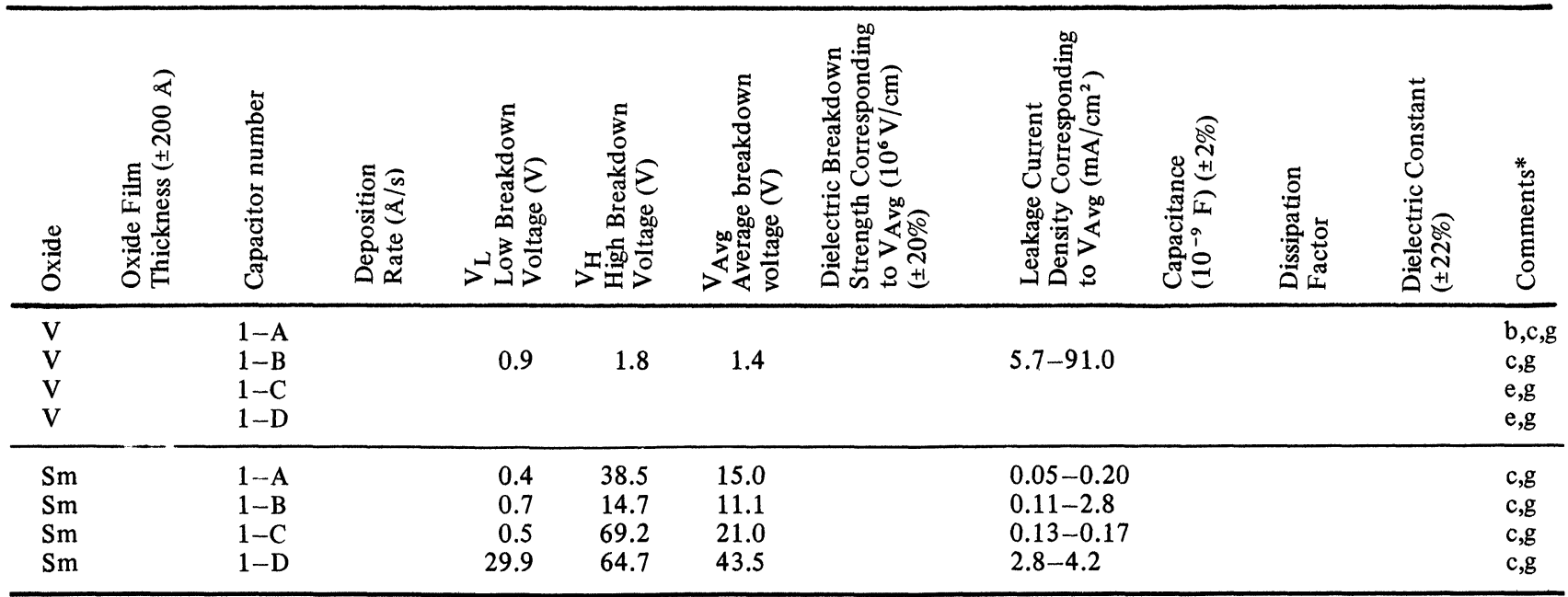

$\dagger$ The quantities within the double line represent average values.

*Comments:-

a-Only one breakdown observed

b-No breakdowns observed up to maximum applied voltage

c-No balance obtainable on capacitance bridge

d-Balance on capacitance bridge questionable

e-Short circuit behavior

f-Open circuit behavior

g-No fringe shift observed in Tolansky interferometer

\subsubsection{Lanthanum oxide Four samples of this} material were prepared, two of which were fabricated with silver electrodes (samples number one and four). No data on thickness, capacitance, or current-voltage behavior could be obtained from the samples with silver electrodes. Both samples prepared with the conventional aluminum electrodes yielded thickness measurements, the approximate values of oxide film thickness being $1300 \AA$ (sample No. 2) and $300 \AA$ (sample No. 3). Capacitance measurements could be obtained on only one electrode of sample number 2 . The balance on the capacitance bridge was dubious and little credence could be given to this measurement and the corresponding value of the dielectric constant. Capacitance measurements were obtained on three electrodes of sample number 3 with values ranging from $6.2 \times 10^{-9} \mathrm{~F}$ to $20.5 \times 10^{-9} \mathrm{~F}$. Two of the corresponding values of the dielectric constant, i.e. 2.3 and 2.2, are in close agreement while the third is larger by approximately a factor of two. In general, the leakage current showed initial erratic behavior but became smoother after several voltage cycles.
3.3.3 Praseodymium oxide Two samples of this material were fabricated, both having an oxide film thickness of approximately $1300 \AA$. Capacitance measurements were obtained on all four capacitors of both samples. These values range from $1.3 \times 10^{-9} \mathrm{~F}$ to $16.0 \times 10^{-9} \mathrm{~F}$. The deposition rates varied by a factor of approximately ten for the two samples. Sample number 1 (deposition rate of $1.1 \AA / \mathrm{s}$ ) yielded a lower dielectric constant (average value 1.5) but had a higher average dielectric breakdown strength $\left(3.9 \times 10^{6} \mathrm{~V} / \mathrm{cm}\right)$. The leakage current for sample number 1 was initially nonlinear and erratic but became more stable and approached linearity after several voltage cycles. Sample number 2 (deposition rate of $10.1 \AA / \mathrm{s}$ ) had an average dielectric constant of 12.1 and an average dielectric breakdown strength of $1.8 \times 10^{6} \mathrm{~V} / \mathrm{cm}$. One capacitor was shorted and the remaining three had leakage current characteristics similar to sample number one.

3.3.4 Neodymium oxide Fourteen samples were fabricated using neodymium oxide as the dielectric 
material. Nine of these samples (samples number 1,2, $3,4,5,6,7,9,12$ ) yielded thickness measurements which varied from 600 to $2300 \AA$. The corresponding values of the relative dielectric constant for the individual capacitors varied from 7.2 to 37.6 . Four samples gave consistent values of the dielectric constant, three of which indicate a value of approximately seven and the other a value of ten. The overall average for all capacitors was found to be 12.7. Leakage current was measured at atmospheric pressure for samples number $1,2,6$, and 11 . These characteristics were initially erratic, with a pronounced nonlinear behavior observed after 5 or 6 voltage cycles. Currents up to $1 \mathrm{~mA}$ at $32 \mathrm{~V}$ were observed. Leakage current data were obtained at pressures ranging from $1.2 \times 10^{-6}$ to $5 \times 10^{-6}$ torr for samples 6,11 , and 12 ; these characteristics were in general much smoother initially than those obtained at atmospheric pressure and exhibited a pronounced nonlinear behavior. Leakage currents up to $1 \mathrm{~A}$ at $4.4 \mathrm{~V}$ were recorded in this non-linear region. The remainder of the samples fabricated were either shorted or showed open circuit behavior and only very limited data were obtained.

\subsubsection{Gadolinium oxide There were seventeen} samples fabricated from this material. Twelve samples (samples number 1 through 5 and 8 through 14) yielded thickness measurements ranging from 600 to $2300 \AA$. Values of the relative dielectric constant ranged from one to above twenty for the individual capacitors with an average value of approximately eleven. Leakage current measurements were obtained at atmospheric pressure for samples number 1, 2, 4, $5,8,10$, and 11 . These varied from being relatively smooth linear curves to nonlinear and erratic behavior. Leakage current data at pressures below $1 \times 10^{-6}$ torr were obtained for samples number $3,12,13$, and 14 ; similar data were obtained at both atmospheric pressure and pressures below $5 \times 10^{-6}$ torr for samples number $9,15,16$, and 17 . These differ markedly; the low pressure measurements were initially smoother (see Section 3.4 for details), and exhibit a pronounced non-linear behavior and a higher conductivity than those obtained at atmospheric pressure.

\subsubsection{Dysprosium oxide Five samples were fabri-} cated from this material. Two samples (samples number 1 and 2) yielded thickness and capacitance measurements. Leakage current data were obtained from both samples. Sample number 1 had an oxide film thickness of approximately $450 \AA$ and was formed at a deposition rate of $0.8 \AA / \mathrm{s}$, while the oxide film thickness of sample number 2 was $1800 \AA$ and was deposited at the rate of $3 \AA / \mathrm{s}$. The values of dielectric constant are consistent for the different capacitors of each sample; however, the average value for sample number 2 was 6.3 , approximately twice that of sample number 1 (2.9). Sample number 2 was completely fabricated in vacuum whereas the oxide layer for sample number 1 was exposed to atmospheric pressure for approximately three hours prior to evaporation of the top electrodes. Leakage current data for sample number 1 were very erratic with dielectric breakdowns occurring at voltages as low as $0.4 \mathrm{~V}$. Corresponding data for sample number 2 were smoother with initial dielectric breakdown occurring no lower than $14.6 \mathrm{~V}$ and up to $53.6 \mathrm{~V}$. This effect due to exposure to the atmosphere prior to evaporation of the counterelectrode is considered to be quite significant.

\subsubsection{Holmium oxide Thickness measurements} were obtained on three of the six samples fabricated from this oxide with values ranging from $600 \AA$ (sample number 5) to $2000 \AA$ (sample number 1). Capacitance measurements varying from $2 \times 10^{-9} \mathrm{~F}$ to $38.1 \times 10^{-9} \mathrm{~F}$ were obtained on eight of the corresponding 12 capacitors. Sample number 1 yielded one value of the dielectric constant (3.1); this value was approximately half that of the average value (7.7) of sample number 4, which showed reasonably consistent values. The three values of the relative dielectric constant obtained from sample number 5 are all less than one and vary by a factor of two. The balance obtained on the capacitance bridge for these capacitors was in each case questionable; therefore, little credence can be given these values. Dielectric breakdown strength was observed to vary from $0.2 \times 10^{6} \mathrm{~V} / \mathrm{cm}$ up to $5.4 \times 10^{6} \mathrm{~V} / \mathrm{cm}$. Leakage current data were obtained on five samples; all of these were nonlinear with voltage and exhibited pronounced erratic behavior.

\subsubsection{Erbium oxide Two samples were fabricated} from this material. Thickness and capacitance measurements were obtained on sample number 1 , the oxide film thickness of which was approximately $1400 \AA$. The evaporation parameters were almost identical for both samples. Capacitance values ranging from $18.2 \times 10^{-9} \mathrm{~F}$ to $31.2 \times 10^{-9} \mathrm{~F}$ were observed on three capacitors of sample number 2 ; a thickness measurement could not be obtained since no fringe shift was observed in the Tolansky interferometer. This was probably due to the thinness of the oxide film as indicated by the large measured capacitance. Sample 
number 1 yielded three values of the relative dielectric constant, two of which were 3.6 and the third 2.7. Leakage current data for this sample were essentially linear with low leakage current $(26 \mu \mathrm{A}$ at $40 \mathrm{~V}$ for a typical capacitor). The capacitors of sample number 2 had a higher leakage current (approximately $200 \mu \mathrm{A}$ at $40 \mathrm{~V}$ ) with a more nonlinear and erratic currentvoltage behavior.

\subsubsection{Ytterbium oxide No satisfactory capacitors} were obtained from the two samples fabricated using this oxide as the dielectric material. Oxide film thickness could not be measured for either sample since no fringe shift was observed in the Tolansky interferometer. Lack of a film thickness measurement prevented making an estimate of the dielectric constant. Capacitance data were obtained on two capacitors from sample number 2 with values of $0.43 \times 10^{-9} \mathrm{~F}$ and $0.23 \times 10^{-9} \mathrm{~F}$. Sample number 1 drew large currents $(38 \mathrm{~mA}$ at $20 \mathrm{~V})$ and exhibited erratic, nonlinear current-voltage behavior. Leakage current for sample number 2 was smaller $(10 \mu \mathrm{A}$ at $20 \mathrm{~V})$ with approximately linear current-voltage behavior over the voltage range investigated $(0$ to $75 \mathrm{~V})$.

3.3.10 Scandium oxide There were a total of four samples fabricated using this oxide. One attempt which proved unsuccessful utilized copper electrodes. No estimates of the dielectric constant are available due to unsuccessful attempts to measure oxide film thickness and capacitance. This material is difficult to evaporate and yielded unsatisfactory capacitors from all four samples investigated. Current-voltage characteristics were essentially linear with a pronounced erratic nature. The most interesting feature was a sharp decrease in current between $0.5 \mathrm{~V}$ and $2 \mathrm{~V}$, corresponding to a pronounced negative resistance or "switching" phenomenon. Optical examination of the samples revealed electrode destruction during this transition.

\subsubsection{Yttrium oxide One sample (sample No. 3)} of the four fabricated using this oxide yielded both thickness and capacitance measurements. The oxide film thickness was $322 \AA$ and capacitance values ranged from $3.4 \times 10^{-9} \mathrm{~F}$ to $5.5 \times 10^{-9} \mathrm{~F}$. The corresponding dielectric constants from this sample are in good agreement, with 1.1 being the average value. Capacitors from sample number 1 drew relatively large currents (a typical observation was $31 \mathrm{~mA}$ at $10 \mathrm{~V}$ ) with an essentially linear behavior. Sample number 3 showed more erratic, nonlinear current-voltage behavior and drew much smaller currents $(10 \mathrm{~mA}$ at $10 \mathrm{~V})$. Leakage current data from sample number 4 were similar to that of sample number 3 . All capacitors from sample number 2 were completely short-circuited. (No attempt was made to remove these shorts by passing of large currents through the capacitor.)

\subsubsection{Vanadium oxide Only one sample was} fabricated from this oxide due to its toxic nature. An evaporation current of only 100 A filled the laboratory with vapors which caused the technician to become dizzy. Although the evaporation of the oxide had to be terminated, a sufficient layer of the oxide was deposited for the sample to be completed and measurements attempted the following day. Current-voltage data were obtained from two capacitors of this sample. Both showed a pronounced nonlinearity with currents up to $50 \mathrm{~mA}$ at $5 \mathrm{~V}$. No successful measurements were made of either oxide film thickness or capacitance.

3.3.13 Samarium oxide Four samples were fabricated utilizing this oxide, two of which were prepared using copper as electrode material. The copper from the top electrode began to disappear quickly, following removal from the vacuum system. No film thickness or capacitance data could be obtained from these capacitors. The two remaining capacitors were fabricated using aluminum as electrode material. No successful measurements were made on any of the resulting capacitors.

\subsection{Steady-State and Vacuum Measurements}

The leakage current ${ }^{\dagger}$ of the oxides of $\mathrm{Nd}$ and $\mathrm{Gd}$ were measured in vacuum at pressures below $5 \times 10^{-6}$ torr without prior exposure to the atmosphere. ${ }^{13}$ In general, current-voltage traces were much smoother than those measured at atmospheric pressure. ${ }^{12}$ The traces showed two distinct regions, a linear lowvoltage "ohmic" region with a gradual transition to a higher voltage region characterized by pronounced non-linearity. The departure from linearity occurred above approximately $1.0 \mathrm{~V}$ for neodymium oxide. Currents up to $25 \mathrm{~mA}$ were observed at this point.

$\dagger$ The data were determined by smoothly varying the voltage over a period of several minutes. The time constants at voltages well below the breakdown voltage were found to be such that the reported results are the same as if they were taken precisely after 5 minutes of voltage application in accordance with International Electrochemical Commission norms. 
Maximum currents of one ampere at $6.75 \mathrm{~V}$ were recorded. For gadolinium oxide the departure from linearity occurred above approximately $0.5 \mathrm{~V}$ with corresponding currents up to $14.4 \mathrm{~mA}$. Currents up to $94 \mathrm{~mA}$ at $8 \mathrm{~V}$ were observed for this oxide in the non-linear region. The conductivity was markedly different at atmospheric pressure and for pressures below $5 \times 10^{-6}$ torr. The leakage current at $3 \mathrm{~V}$ and $5 \times 10^{-7}$ torr was $9.3 \mathrm{~mA}$ for capacitor Gd-15-B, whereas the current at the same voltage and atmospheric pressure on this sample was observed to be only $25 \mu \mathrm{A}$. This represents a decrease in oxide conductivity by a factor of 370 with increase in pressure. Factors for the decrease in conductivity upon raising the pressure to atmospheric pressure were typically in the range of 3 to 300 . This evidently reflects the factor of nonstoichiometry in the evaporated oxides.

\section{SUMMARY AND CONCLUSIONS}

On the basis of the experimental survey conducted, the oxides of $\mathrm{Ce}, \mathrm{La}, \mathrm{Nd}, \mathrm{Gd}, \mathrm{Pr}$, and Er show the greatest promise from those studied as dielectric materials for thin-film capacitors. Cerium oxide, the most abundant of the rare earth oxides, evaporates with relative ease and has the highest average dielectric constant (19.0) of the oxides investigated. Lanthanum oxide is slightly harder to evaporate (lanthanum oxide required $180 \mathrm{~A}$ through the tungsten boat compared to $150 \mathrm{~A}$ for cerium oxide), but shows a very high dielectric breakdown strength (approximately $8.7 \times 10^{6} \mathrm{~V} / \mathrm{cm}$ ) and a very good capacitance. Neodymium oxide has a good average dielectric breakdown strength $\left(3.4 \times 10^{6} \mathrm{~V} / \mathrm{cm}\right)$, high capacitance, and an average dielectric constant of 11.8 , which is approximately twice that of $\mathrm{SiO}(6.0)$. Gadolinium oxide has a dielectric breakdown strength of the order of $3 \times 10^{6} \mathrm{~V} / \mathrm{cm}$ and an average dielectric constant of 8.2. (Gadolinium oxide required $193 \mathrm{~A}$ for evaporation, slightly higher than the $180 \mathrm{~A}$ required for neodymium oxide.) Praseodymium oxide has an average dielectric breakdown strength of $3.2 \times$ $10^{6} \mathrm{~V} / \mathrm{cm}$ and an average dielectric constant which varied with deposition rate from 1.6 for $1.1 \AA / \mathrm{s}$ to 12.1 for $10.7 \AA / \mathrm{s}$. Erbium oxide has an average dielectric breakdown strength of $4.7 \times 10^{6} \mathrm{~V} / \mathrm{cm}$ and an average dielectric constant of 3.5. Both erbium and praseodymium oxide require approximately 185 A for evaporation.

The ratio of satisfactory capacitors (a satisfactory capacitor is one which yielded comprehensive currentvoltage and capacitance data) to total number fabri- cated for each oxide provides a figure of merit to aid in the evaluation of the results. These figures (expressed in per cent) are tabulated in Table III. These numbers are not to be interpreted as statistically meaningful, but are merely some measure of the worth of each oxide as a reliable dielectric

TABLE III

Figure of merit $\dagger$ for the oxides investigated

\begin{tabular}{lc}
\hline Oxide & Figure of Merit $(\%)$ \\
\hline $\mathrm{Ce}$ & 75 \\
$\mathrm{La}$ & 62 \\
$\mathrm{Pr}$ & 100 \\
$\mathrm{Nd}$ & 71 \\
$\mathrm{Gd}$ & 88 \\
$\mathrm{Dy}$ & 40 \\
$\mathrm{Ho}$ & 33 \\
$\mathrm{Er}$ & 88 \\
$\mathrm{Yb}$ & 0 \\
$\mathrm{Sc}$ & 0 \\
$\mathrm{Y}$ & 25 \\
V & 0 \\
Sm & 0 \\
\hline
\end{tabular}

$\dagger$ Figure of Merit is defined as the ratio of satisfactory capacitors to total number of capacitors fabricated. A satisfactory capacitor is one which yielded capacitance and current-voltage measurements. These numbers are not intended to be statistically meaningful, but are included merely as some measure of the worth of each oxide as a reliable dielectric material when prepared under our experimental conditions.

material for thin film application. From Table II it can be seen that dysprosium and holmium oxide both exhibit good dielectric properties. However the difficulty experienced in evaporating these oxides along with a low figure of merit caused these oxides to be excluded from the list of those considered to be promising.

\section{SUGGESTIONS FOR FURTHER STUDY}

The properties of thin film capacitors have been observed to depend, among other parameters, on oxide film thickness, evaporation pressure, deposition rate (cf. Table II), and impurities present during evaporation. ${ }^{1,2,18,19}$ Optimization of these parameters should lead to a more reliable capacitor. The first step would be to determine the functional dependence of dielectric constant, breakdown 
strength, and the overall performance of a capacitor on each of these parameters. The role of impurities could be determined by pumping an ultra-high vacuum system to $10^{-10}$ torr or lower and then introducing a selected gas into the system to a partial pressure similar to the background partial pressure of this particular gas in a conventional $10^{-6}$ torr evaporator. Evaporation and subsequent measurement would then be carried out according to standard procedure.

A general lack of understanding of the current transport and dielectric breakdown mechanisms in thin film capacitors suggest the initiation of further basic experiments along these lines. A particularly fruitful experiment would be to determine the gaseous and solid products given off from a capacitor during breakdown. This could be accomplished by continuously monitoring with a quadrapole residual gas analyzer the gases ejected into an ultra-high vacuum during dielectric breakdown. The ultra-high vacuum system is necessary to prevent background gases from masking the volatile decomposition products of dielectric breakdown. Following breakdown, the neighborhood of the breakdown spot should be analyzed using x-ray diffraction techniques to ascertain the degree to which the oxide and electrode material have crystallized, recrystallized, or chemically reacted. The role of conduction channels, heating, and subsequent decomposition of the dielectric material should be clarified by such experiments.

\section{ACKNOWLEDGEMENT}

This applied research was supported by NASA Contract 8-20061.

\section{REFERENCES}

1. P. J. Harrop, Dielectrics (John Wiley and Sons, N.Y., 1972).

2. Handbook of Thin Film Technology, L. I. Maissel and R. Glang, editors (McGraw-Hill Book Company, N.Y., 1970).

3. D. Gerstenberg, Thin Film Capacitors, Ch. 19 in Ref. 2 above.

4. P. J. Harrop and D. S. Campbell, Thin Solid Films 2, 273 (1968).

5. P. J. Harrop and D. S. Campbell, Dielectric Properties of Thin Films, Ch. 16 in Ref. 2 above.

6. M. B. Panish, J. Chem. Phys. 34, 1079 (1961); 34, 2097 (1961).

7. P. N. Walsh, H. W. Goldstein, and D. White, J. Am. Ceram. Soc. 43, 229 (1960).

8. G. Hass, J. B. Ramsey, and R. Thun, J. Opt. Soc. Am. 49, 116 (1959).

9. J. C. Rairden, J. Electrochem. Soc. 114, 75 (1967).

10. C. Feldman and M. Hacskaylo, Rev. Sci. Instr. 33, 1459 (1962).

11. M. Hacskaylo and R. C. Smith, J. Appl. Phys. 37, 1767 (1966).

12. A. T Fromhold, Jr., W. D. Foster, T. A. Harbuck, and R. B. Mosley, Proc. 6th Rare Earth Research Conference, Gatlinburg, Tennessee (1967) p. 591.

13. A. T. Fromhold, Jr., W. D. Foster, and J. L. Bilodeau, Bull. Am. Phys. Soc. 12, 547 (1967).

14. A. T. Fromhold, Jr., Physica Status Solidi 36, K129 (1969).

15. A. T. Fromhold, Jr. Theory of Metal Oxidation. Vol. I. Fundamentals (North Holland Publishing Company, Amsterdam, 1976) pp. 273-274.

16. S. Tolansky, Multiple Beam Interferometry of Surfaces and Films (Oxford University Press, London, 1945) p. 224

17. W. L. Silvernail and R. M. Healy, Cerium (A report prepared for the Encyclopedia of Chemical Technology by American Potash and Chemical Corporation, West Chicago, Illinois, 1963) p. 2.

18. F. W. Schenkel, Electronics, 38, 67 (1965).

19. L. Holland, Vacuum Deposition of Thin Films (Chapman and Hall, Ltd., London, 1963). 

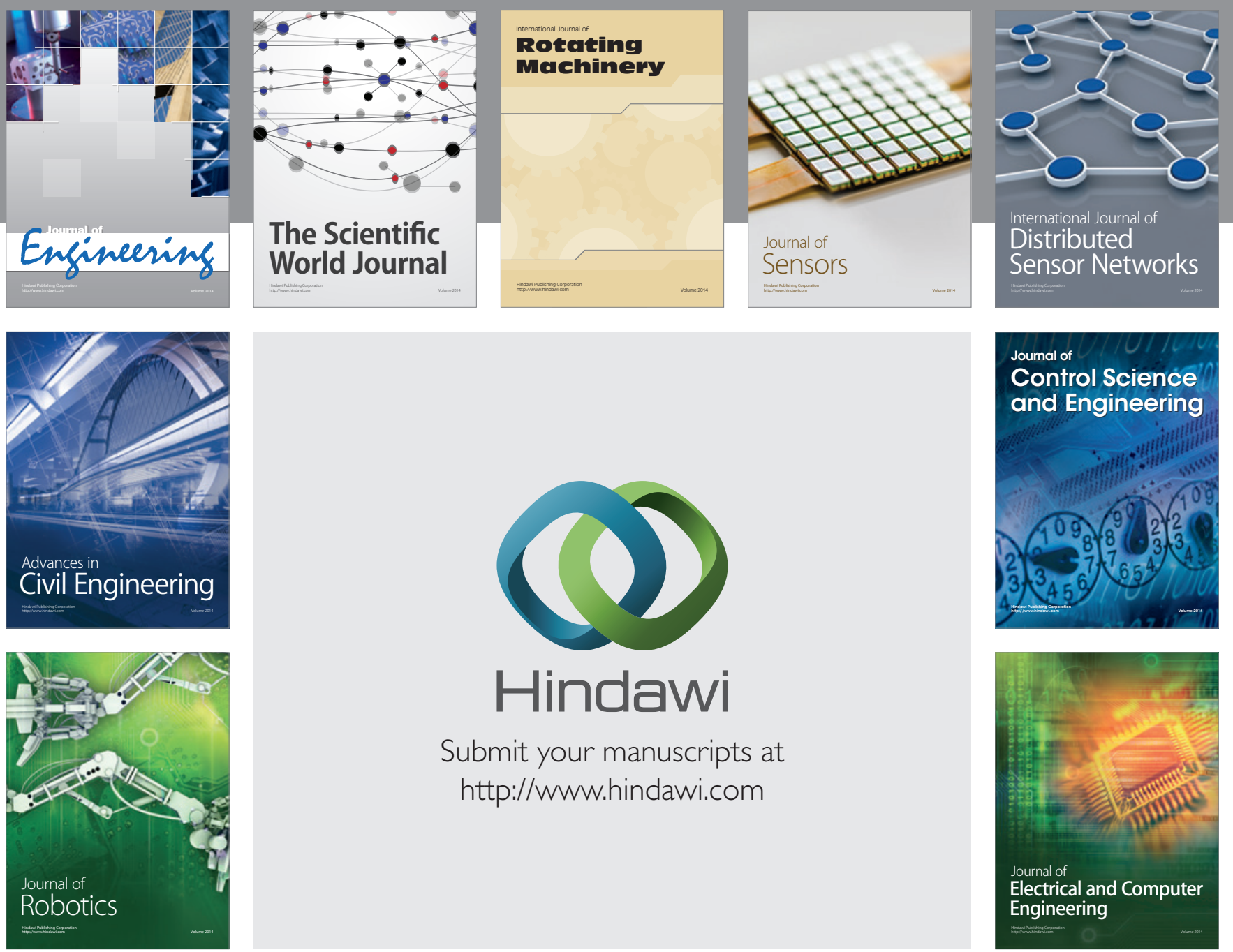

Submit your manuscripts at

http://www.hindawi.com
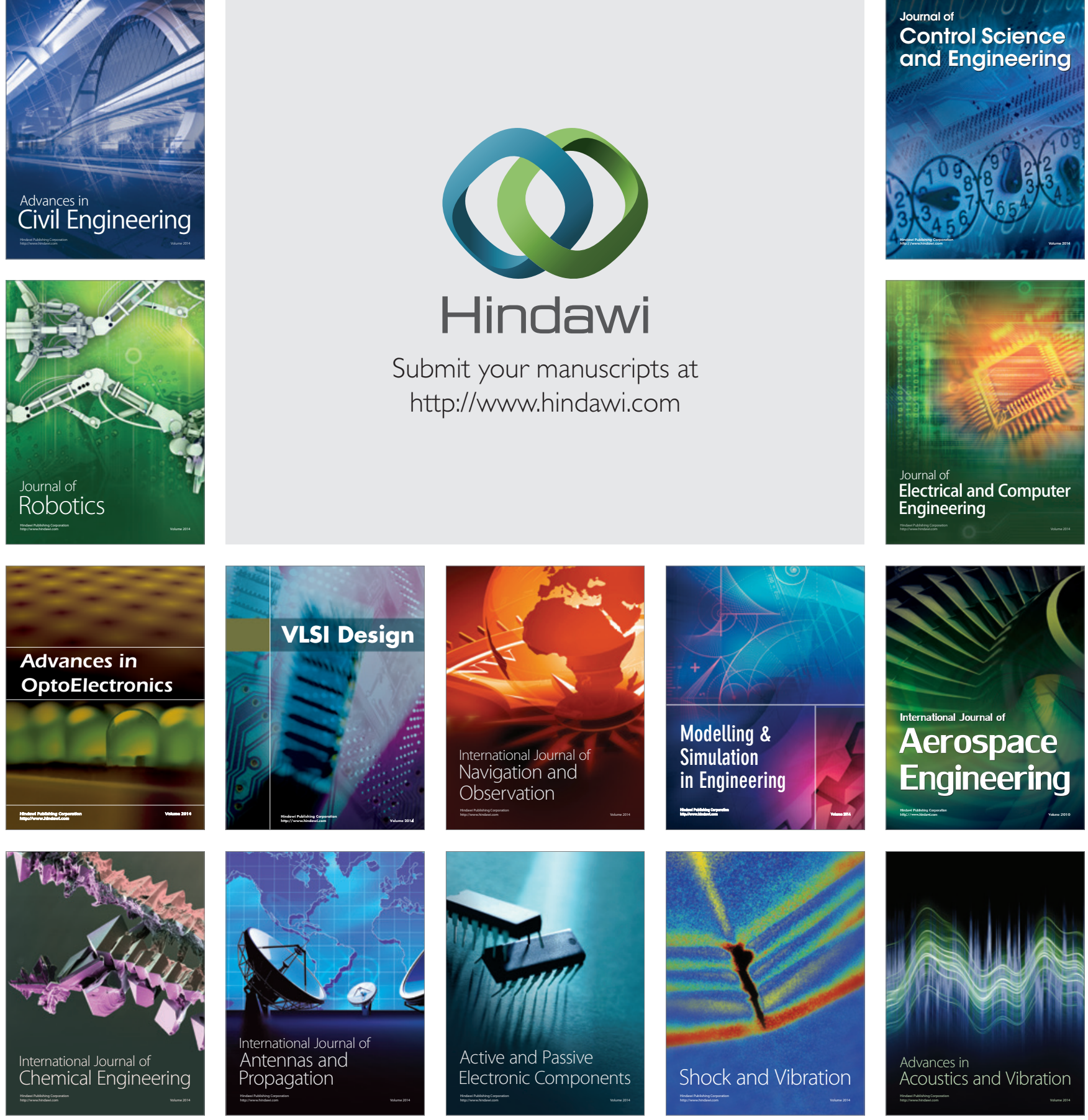